\title{
Human Foetal Growth
}

\section{By A. М. Тномson, Department of Midwifery, University of Aberdeen}

\section{The general picture}

After fertilization, the dividing ovum floats in the intra-tubal and intra-uterine fluids for a few days and then becomes embedded in the uterine wall. Supplies of water, oxygen and nutrients for the embryo are assured by the trophoblast in contact with maternal blood and soon by the placenta. Within about 3 weeks of implantation the beginnings of the foetal circulation are established. From this point, until a late stage of pregnancy, the supply system seems to keep well ahead of demands. At first, embryonic differentiation is more important than growth in size, and all the main organs and tissues are formed before the end of the ist trimester, when the foetus weighs only about $20 \mathrm{~g}$. I can only touch on an interesting aspect of this early stage, the role of organizer substances and their relation to nutrition. Chemical substances control the differentiation of various parts of the embryo. Interference with organizer effects during critical phases of development, e.g. by lethal genes, the action of some viruses, or even by local injury, is probably the cause of some of the so-called congenital abnormalities. Certain vitamins seem to behave as organizers during specific phases of development. Warkany (1945) has produced a number of developmental defects in foetal rats by restricting riboflavin intake to a critical degree during a short critical period of gestation, and similar effects have been noted in pigs as a result of vitamin A restriction (Hale, 1935). A detailed account of organizer action is given by Needham (1942); a lucid summary can be found in Corner's (1944) remarkable 'embryologist's essay on man'.

The initial phase of differentiation is succeeded by a phase of maturation and growth in size. Flexner, Cowie, Hellman, Wilde \& Vosburgh (1948) showed that placental permeability to radioactive sodium increases some seventyfold between the 9 th and 36 th weeks of pregnancy, followed by a decline, towards term, associated with degenerative changes in the placenta. Although it seems that the supply mechanism becomes markedly less efficient near term, at the same time the greatest actual bulk of new foetal tissue is being produced. During the last few weeks of pregnancy, therefore, the rate of growth of the foetus is more likely to be affected by limitation of supplies.

It should be noted, however, that the nutritional demands of the foetus are never very large. At mid-pregnancy the heat of combustion of the foetal body is only about $160 \mathrm{Cal}$. and at term it is only about $4000 \mathrm{Cal}$. (Fig. I, curve $C$ ). 'The protein content of the full-term foetus is about $360 \mathrm{~g}$. and the calcium content about $25 \mathrm{~g}$. Even if the efficiency of conversion of nutrients into foetal tissue is low, the absolute demands by the foetus itself on the maternal supplies cannot amount to much. Too much may be made of the concept of foetal competition for supplies, which cannot be serious unless the mother's reserves are low and she is eating a diet barely adequate for herself. (The dircet demands of the foetus are not, of course, the whole story of maternal requirements during pregnancy.) 


\section{Normal foetal growth}

Fig. I, curves $A$ and $B_{1}$, shows average growth curves for length and weight of the type quoted in most standard texts. Both are fairly smooth curves. The inflexion at mid-pregnancy in the crown-rump length curve is probably due to a slight slowing of trunk growth as the growth of the limbs accelerates. The weight curve is shown as

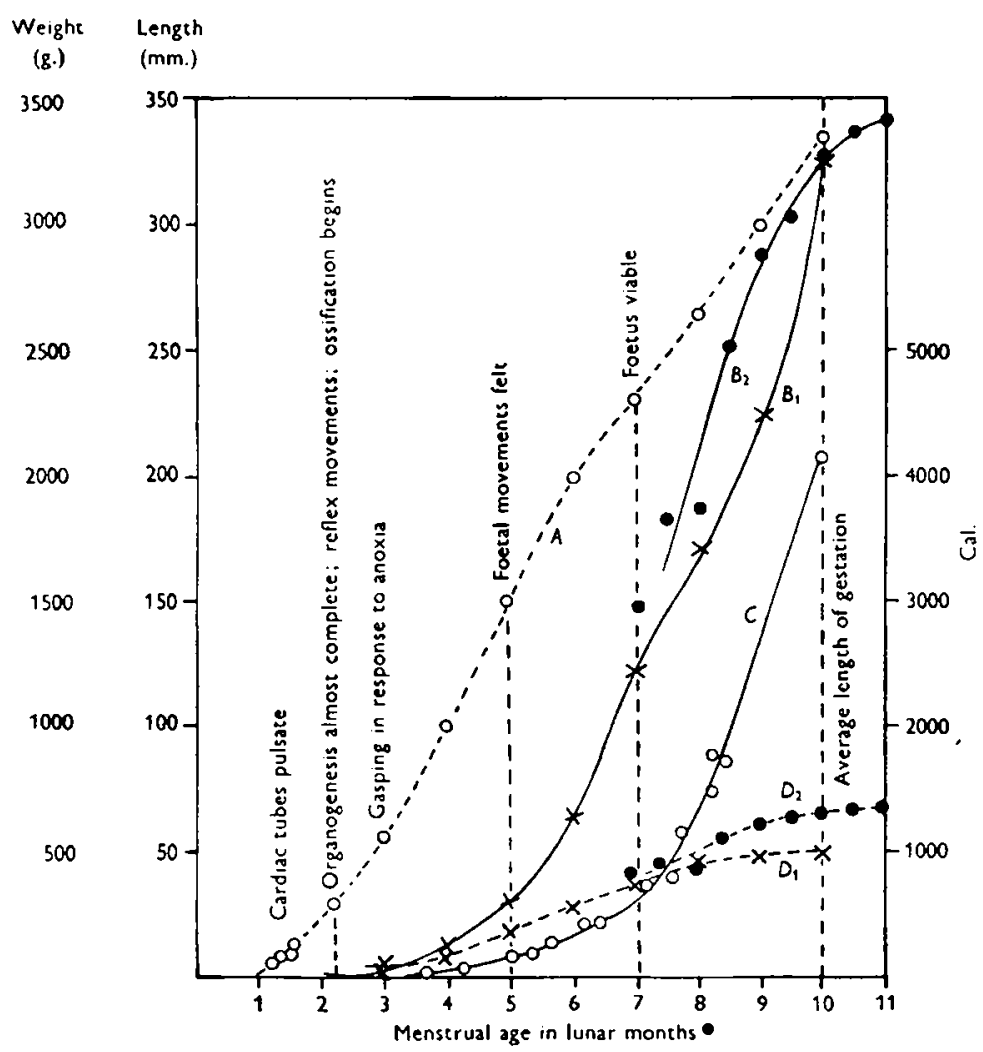

Fig. I. Growth and development of foetus and placenta. $A, O \ldots-$, foetal crown-rump length, $\mathrm{mm}$. (Leitch, 1950); $B_{1}, \times-\times$, foetal weight, g. (Leitch, 1950). $C, \bigcirc \longrightarrow$, foetal heat of combustion, Cal. (Leitch, 1950). $D_{1}, \times-\ldots \times$, placental weight, g. (Hecker, 1866). $B_{2},-\longrightarrow$, foetal weight, g.; $D_{\mathbf{2}}$, 1948-9 (excluding twins and gross deformities).

- Menstrual age connotes the interval between the ist day of the last menstrual period and the day of delivery.

steepest during the final month of pregnancy, and if this is correct the foetus puts on about $0.6 \mathrm{~kg}$. $(\mathrm{r} \cdot 3 \mathrm{lb}$.) during the last 2 weeks, which is not in accordance with obstetric experience. I have inserted data from Aberdeen Maternity Hospital for first single births to married women (curve $B_{2}$ ). This confirms the finding of Hosemann (I948), that the curve for average birth weights is sigmoid. Hosemann's data suggest that average birth weights actually decline after the I i th lunar month. Though such curves, constructed for average birth weights, do not necessarily prove that the growth of the individual foetus follows the same pattern, there is reason to believe that the rate of growth becomes less during the final stage of gestation. Clinically, there is no evidence 
of exceedingly rapid foetal growth during the terminal phase. Curves $D_{1}$ and $D_{2}$ show that the growth of the placenta slows down towards term, and the data of Flexner et al. (I948), already cited, suggest that its functional efficiency also declines during the final stages. If the foetal supply mechanism is becoming less efficient, it would be surprising if growth continued unimpaired. Incidentally, curve $D_{1}$ is constructed from the only figures I have been able to find for placental growth, and these are 84 years old. Curve $D_{2}$ shows average placental weights in the group of Aberdeen cases.

Barcroft (1946) has said that such total-growth curves give only limited information, since they conceal the individual characteristics of the growth patterns of organs and tissues. Knowledge of organ and tissue growth in the human foetus is limited. Most of the essential organs, and particularly the brain, form a large proportion of the total body size at first, the proportion declining as gestation proceeds. Changes of body constitution in response to nutritional influences, such as those reported for the foetal lamb by Wallace (1946) have not been worked out. Clatworthy \& Anderson (1944) have summarized knowledge of the differential growth rates of organs and tissues in the human foetus.

What is the scatter round the average curves shown in Fig. $x$ ? Barcroft (1946) has given data indicating that the dispersion of weights of foetal lambs is relatively small during the greater part of gestation, but during the last 2 or 3 weeks there is a remarkable increase of scatter, so that the newborn lamb can weigh anything from about 2 to $7 \mathrm{~kg}$. In his own words: 'These facts are, I think, best explained by supposing that as term approaches some of the foetuses have faltered.' Wallace (r 948 ) and Thomson \& Thomson (1948-9) have shown that sharply contrasted maternal diets during the latter part of pregnancy produce a marked difference in the average birth weights of lambs. The latter authors, however, point out that there is a considerable overlap of the individual birth-weight data for the two nutritional groups (for singles and twins separately, all sheep being of the same breed), so that some poorly fed ewes produce lambs as big as some well-fed ewes. Data for the variations in human foetal weights throughout gestation do not appear to have been published. Hosemann (1948) gives curves showing the distribution round the median during the last trimester; it would appear from these that the dispersion is no less at 28 weeks than at 40 weeks. My obstetrical colleagues tell me that they have not been impressed by any similarity of size between very immature foetuses of allegedly similar gestational age. There is therefore a possibility that, unlike the sheep foetus, the human foetus shows marked differences of growth throughout gestation.

The variation in birth weights of full-term infants is certainly striking. Fig. 2 gives the frequency distribution of full-term birth weights among 766 Aberdeen primiparas whose lengths of gestation were considered to be reliably known.

\section{Technical difficulties in assessing growth rates}

The literature is full of information on birth weights, but the data are almost never adequately broken down by length of gestation, so that it is very difficult to draw conclusions as to foetal growth rates. Fig. I indicates that quite small differences of foetal age can introduce large differences in size. Knowledge that the mean lengths of 
gestation in two groups to be compared are similar does not help much, since growth near term is not steady in relation to time.

The determination of the length of gestation in human patients is difficult. The exact date of fertile intercourse is seldom known, and the assumption that fertilization takes place $\mathrm{I}_{4}$ days after the ist day of the last menstrual period is only roughly true, even in the absence of menstrual irregularities. Apart from such inherent difficulties, ordinary practice is often very inexact. The expected date of delivery is worked out by rule of

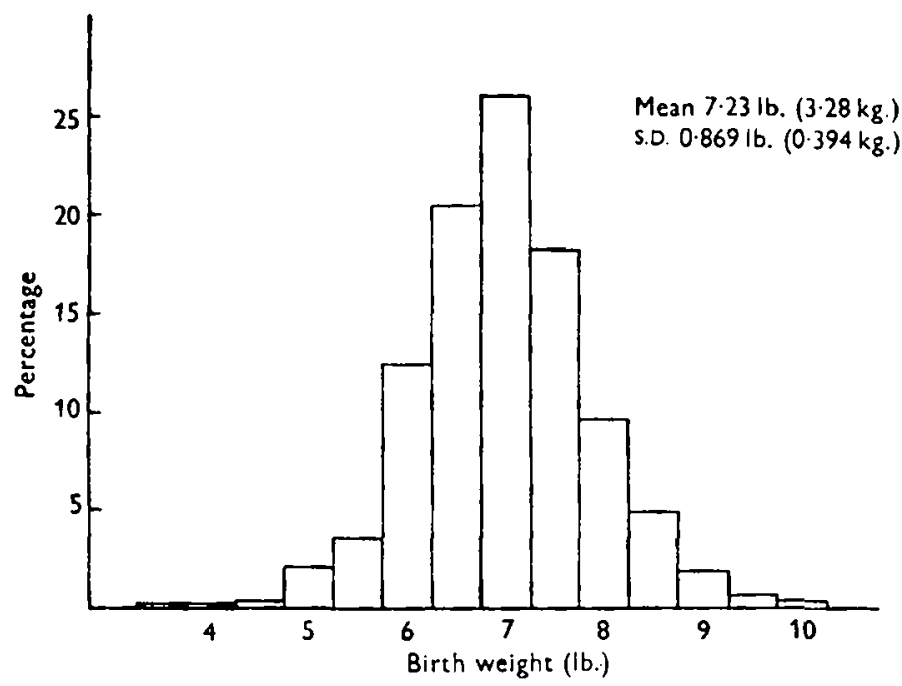

Fig. 2. Distribution of birth weights among babies of 766 Aberdeen Maternity Hospital primiparas delivered at $280 \pm 7$ days. Twins, seriously deformed infants, and cases where the menstrual age (see Fig. I) was doubtful have been excluded.

thumb from the patient's stated date of last menstruation. Some patients do not know that the Ist day is wanted; many do not remember exactly; and some give the wrong date in an effort to conceal pre-marital conception. When the child is born, its maturity is worked out by rough and ready mental arithmetic relating the date of delivery to the expected date; and if the birth weight is unusually high or low an arbitrary correction is quite likely to be made, on the assumption that 'the dates must be wrong'. The procedure we have adopted in our cases is to cross-question the patient on the reliability of her menstrual date, to check her statement, when possible, against the clinical findings during pregnancy, and to use exact methods for calculating the interval between the last menstrual period and the date of delivery. 'Uncertain' cases are not included in the series reported here. Though the exactness of our methods is recognized to be relative only, it is difficult to see how greater accuracy can be achieved in routine practice, and it is probable that the interval is correct to within a few days in most of the cases.

Finally, it should be noted that weight is highly labile, and is, in some ways, the least satisfactory measure of growth. We badly need reliable data on the skeletal measurements of babies of known gestational age. 


\section{Factors causing variations of foetal growth}

Part of the great variation in birth weight observed in the full-term foetus is likely to be due to errors in the estimation of foetal age, despite the precautions noted above. But the standard deviation of the observations is about I lb. (see Fig. 2), and it is most unlikely that errors in the estimation of foetal age could account for more than a small proportion of the variance. All the Aberdeen infants were weighed on lever balances in hospital. It can be concluded, therefore, that most of the apparent variability of growth really exists. The possible causes will be examined.

\section{Genetic factors}

Sex is the only inherited factor about which we know much. Boys grow slightly faster than girls. In the Aberdeen series the mean weights at $280 \pm 7$ days were: boys, $7.38 \pm 0.88 \mathrm{zlb} .(3.35 \pm 0.400 \mathrm{~kg}$. $)$; girls, $7.07 \pm 0.828 \mathrm{lb}$. $(3.21 \pm 0.376 \mathrm{~kg}$.). It is likely that a genetically determined growth potential accounts for some part of the variability, but its relative importance is unknown at present.

\section{Maternal age and parity}

All the Aberdeen data quoted are for primiparas. Their analysis supports the usual view that any effect which maternal age may have is so slight as to be swamped by other factors. I have not worked out any figures for different parities. The literature suggests that second babies tend to be slightly heavier than first (Martin, 1930-1).

\section{Maternal size}

Walton \& Hammond's (1938) well-known experiment with Shetland-Shire horse crosses showed that the size of the newborn foals, under conditions of extreme genetic variability, is determined by the size of the mother and her capacity to nourish and sustain the foetus. Baird (1945) showed that human birth weights, for all menstrual ages*, vary according to the height of the mother. I have worked out similar data for full-term infants only. Fig 3 shows that average birth weights ( and hence the foetal growth rates) increase as maternal height increases. In an earlier and smaller series, $\mathrm{Mr} \mathrm{M}$. $\mathrm{H}$. Quenouille determined for me the regression of birth weight at term on maternal height and width of the pelvis at the iliac crests. He found a small but highly significant correlation with height; the pelvic measurement, however, contributed nothing to the prediction of birth weight. It should be noted that the standard deviations in each height group (Fig. 3) and for all heights together (Fig. 2) are similar. Thus height by itself does not account for much of the variability in birth weights.

\section{Maternal health}

Height signifies more than mere size. We have recently been grading mothers appearing at the antenatal clinic in terms of physique and general physical well-being. The assessment, being subjective, is necessarily rough, but the numbers along the

- Menstrual age connotes the interval between the Ist day of the last menstrual period and the day of delivery. 
bottom of Fig. 4 show that 70 out of $162(43.2 \%)$ of tall women were assessed as 'good'; whereas only 14 out of $122(\mathrm{II} \cdot 5 \%)$ of short women were in the 'good' category. 'The most probable interpretation is that well-nourished women are well-grown as well as healthy, whereas the ill-nourished are not only stunted but do not have the appearance of vigorous health. The same figure shows graphically the average birth weights in each physical grade arranged by height. Women graded as 'good' tend to have larger babies,

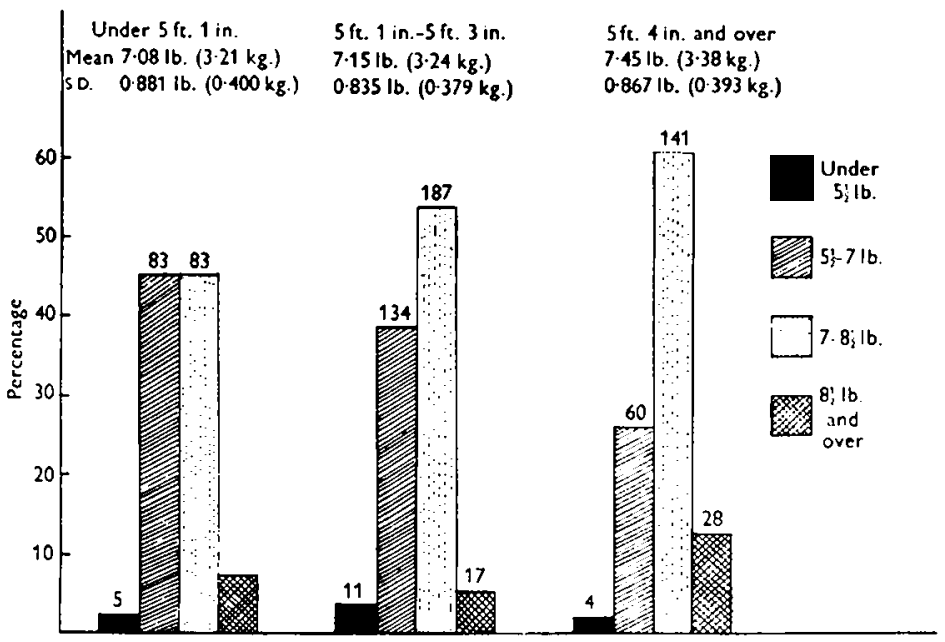

Fig. 3. Maternal height and birth weight at $280 \pm 7$ days. (Aberdeen Maternity Hospital primiparas.) Figures above columns are numbers of cases.

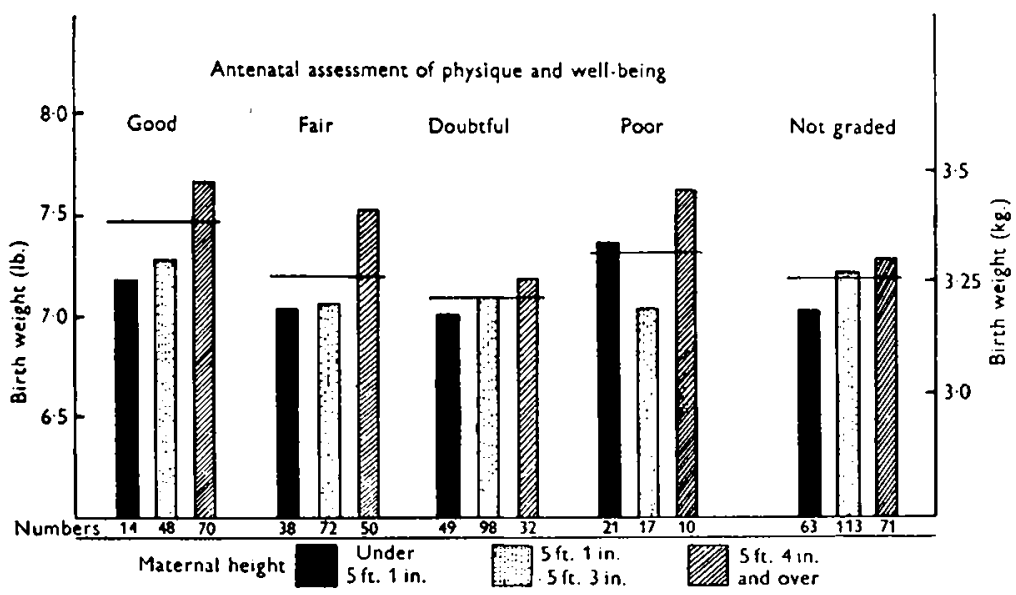

Fig. 4. Average birth weights according to maternal height and physical well-being. (Aberdeen Maternity Hospital primiparas delivered at $280 \pm 7$ days.) Cross-line in each group represents the mean of the group.

and this is true for each height group separately. Down to the grading 'doubtful' there is the appearance of a fairly regular decrease of average birth weight as physical condition deteriorates. The increase of average birth weights among 'poor' patients is presumably a random variation. The numbers are small. 


\section{Pathological conditions}

That large babies of low vitality are borne by diabetic mothers is well known (Lawrence \& Oakley, 1942). I have not found any data showing whether foetal growth is altered in other pathological states of the mother. Many obstetricians believe that the baby tends to be small when the mother is hypertensive. I have no data on this point, but examination of the hospital records makes it clear that if this is a rule, there are many exceptional cases. I am inclined to think that the weight change of the mother is related to the foetal growth rate and there is support for this view in the literature (Beilly \& Kurland, 1945); but once again, if this is a rule, exceptions are frequent.

\section{Maternal nutrition}

Stature and physical health are, to some extent, indices of the state of nutrition, past and present, since well-nourished people tend to be tall and in good health. The data presented above suggest that though the maternal plane of nutrition affects the foetal growth rate, it does not account for anything like the total variation. On the other hand, Burke, Harding \& Stuart (r943), working in Harvard, claim that birth weights (the gestational ages are not stated) are closely related to the protein content of the maternal diet during pregnancy. Sontag \& Wines (1947), also in America, found only an insignificant correlation, and raise doubts as to the reliability of the technique of Burke $e t$ al. We have been carrying out diet surveys on Aberdeen primiparas by weighing the food consumed for $I$ week during the 7 th month of pregnancy. Only those mothers considered to have kept reliable records are included in Table $\mathrm{I}$, the first part of which

Table I. Average birth weights of infants arranged according to mother's daily intake of protein $(a)$ and calcium $(b)$ estimated during the $7^{\text {th }}$ month of pregnancy

(Aberdeen married primiparas, 1948-50)

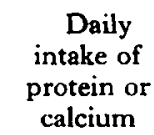

(g.)

Under 70
$70-88 \cdot 9$
90 and over
Under $0 \cdot 800$
$0 \cdot 8-1 \cdot 199$
$1 \cdot 200$ and over

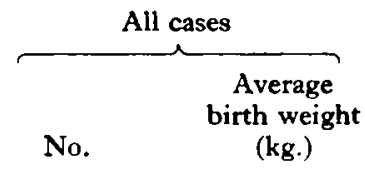

(a) Protein

39
67

39

(b) Calcium

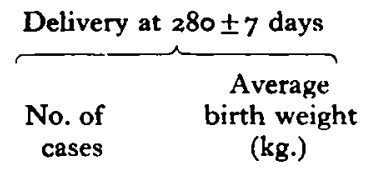

$\begin{array}{ll}23 & 3.32 \\ 37 & 3.23 \\ 17 & 3 \cdot 29\end{array}$

$\begin{array}{ll}16 & 3.25 \\ 36 & 3.32 \\ 25 & 3.21\end{array}$

shows the average birth weights of babies born to women in three different proteinintake categories. No correlation is evident; and the same holds when the diets are grouped according to calcium content.

Diets in Aberdeen are, on the whole, pretty adequate. It may be that the absence of correlation is because almost all our mothers are at least adequately fed at the present time. Under conditions of severe dietary restriction foetal growth may be depressed. 
But an extensive literature on birth weights during the war and famine conditions scarcely supports the view that foetal growth is sensitive to anything except very drastic restrictions of diet during pregnancy, and even then the depression of growth would not account for the large variation observable in a well-fed community.

\section{General conclusions}

The data presented indicate that there are gross variations in foetal growth under ordinary conditions, of such a degree that one full-term baby may be twice as heavy as another. A small part of this variability is probably due to errors in the estimation of foetal age, but even so a residual real variability of large dimensions remains. Its causes are probably complex. Maternal stature and physical health, both of which are doubtless conditioned to an important degree by nutrition during childhood and adult life, seem to produce a shift in the mean foetal growth rates which is small in relation to the range, and to have little effect on variability. Diet in pregnancy, at all events within the limits of ordinary dietary habits among a reasonably well-nourished population, seems to have an even smaller influence. Claims that foetal growth is readily influenced by changes in diet during pregnancy do not seem to be justified.

These conclusions must be taken in their proper perspective. One may recast them as follows:

(1) The maintenance of a high nutritional level among women generally is probably of considerable importance. If the mean birth weight of the group of babies shown in Fig. 2 were raised by $0.5 \mathrm{lb}$. $(0.23 \mathrm{~kg}$.) without changing the distribution round the mean, an effect which might be produced by prolonged good feeding, the incidence of 'premature' babies, that is, those weighing under $5.5 \mathrm{lb}$. $(2.5 \mathrm{~kg}$.) at birth would be reduced from 2.61 to $0.52 \%$. (These figures apply only to full-term babies. The overall incidence of prematurity among Aberdeen primiparas is about $10 \%$. Nutritional improvement would probably not only increase the average rate of foetal growth but also prolong the average gestation period.)

(2) The nutritional level of the individual patient is a poor guide to the probable birth weight of her baby. A change in her diet during pregnancy, within reasonably safe and practical limits, is unlikely to influence the weight of her baby at term by more than a few oz., an effect which has little clinical importance in labour. Good and abundant feeding in pregnancy cannot guarantee the delivery of a big baby, nor restriction of diet necessarily produce a small one. If a small baby is desired in the interests of an easy confinement, it is more certain, and probably safer, to induce labour early than to restrict the mother's diet.

(3) Education of patients in the desirability of good feeding during pregnancy is therefore scarcely worth considering as a means of manipulating the birth weights of individual babies. But such education may have a valuable social effect if carried out routinely on all patients, e.g. through a reduction in the incidence of premature babies.

I have said nothing about the vitality of infants and its relationship to foetal growth. Clinical experience indicates that variations in 'quality' among babies are just as marked as variations in size, and probably of more practical importance. Vitality is difficult to measure, but its study in relation to growth and morphology would certainly be valuable. 


\section{REFERENCES}

Baird, D. (1945). F. Obstet. Gynaec. Brit. Emp. 52, 339.

Barcroft, J. (1946). Researches on Pre-natal Life. Oxford: Blackwell Scientific Publications.

Beilly, J. S. \& Kurland, I. I. (1945). Amer. F. Obstet. Gynec. 50, 202.

Burke, B. S., Harding, V. V. \& Stuart, H. C. (r 943). F. Pediat. 23, 506.

Clatworthy, H. W. Jr. \& Anderson, R. G. (1944). Amer. Y. Dis. Child. 67, 167.

Corner, G. W. (1944). Ourselves Unborn. London: Humphrey Milford.

Flexner, L. B., Cowie, D. B., Hellman, L. M., Wilde, W. S. \& Vosburgh, G. J. (1948). Amer. F. Obstet. Gynec. 55, 469 .

Hale, F. (1935). Amer. F. Ophthal. 18, 1087.

Hosemann, H. (1948). Arch. Gynäk. 176, 109.

Hecker, C. (1866). Quoted by J. Needham (1931) in Chemical Embryology, Vol. 3. Cambridge: University Press.

Lawrence, R. D. \& Oakley, W. (1942). Quart. F. Med. I1, 45.

Leitch, I. (r950). In Combined Text Book of Obstetrics and Gynaecology, ch. 7 [D. Baird, editor]. Fdinburgh: Livingstone.

Martin, W. J. (1930-I). Ann. Eugen., Camb., 4, 327.

Needham, J. (1942). Biochemistry and Morphogenesis. Cambridge: University Press.

Sontag, L. W. \& Wines, J. ( 1947). Amer. F. Obstet. Gynec. 54, 994.

Thomson, A. M. \& Thomson, W. (1948-9). Brit. F. Nutrit. 2, 290.

Walton, A. \& Hammond, J. (1938). Proc. roy. Soc. B, 125, 311.

Wallace, L. R. (1946). F. Physiol. ro4, 33 P.

Wallace, L. R. (1948). F. agric. Sci. 38, 93.

Warkany, J. (1945). Vitamins and Hormones, 3, 73.

\section{Secular Changes in Growth}

BY J. B. DE V. WEIR, Institute of Physiology, University of Glasgow

This contribution is printed by title only since it has been submitted for publication as an original paper. 